\title{
Model Development for Combined University Admission System in Respect of Bangladesh
}

\author{
SAGOR MAHMUD ${ }^{1}$, ASHIKUR RAHMAN KHAN $^{1,}$ *, \\ MAHAMUDUL HASAN RANA ${ }^{2}$, MAINN UDDIN ${ }^{1}$ \\ ${ }^{1}$ Department of Information and Communication Engineering \\ ${ }^{2}$ Department of Computer Science and Telecommunication Engineering \\ Noakhali Science and Technology University \\ Noakhali-3814 \\ BANGLADESH
}

\begin{abstract}
The intake system of our public university is each university conduct individual admission test. Each university has its self-admission test system. The student has to take part in the admission test for a particular subject and individual faculty of a university. In this scenario, the student has to take part in many admission tests. It's tough, time-consuming and costly to participate in many admission tests. In this circumstance, it's very much essential to discover a different or alternative process so that we can come out from such botheration and hassles. No method has been developed yet to release from these complexities and problems. This paper presents the issues of traditional admission system and how to solve this problem. To get a highly accurate model, admission related data is collected, then data is filtered, analysis and several experiments were executed. In this paper, we proposed three models that serve as the core design for the university admission system and then it is checked by a survey form, whether the model validates the requirements or not. The integrated admission system is convenient among three models. This model can reduce the limitation of the traditional admission system and provide a quality admission process.
\end{abstract}

Key-Words: - Entrance Examination, Higher Education, University Admission.

Received: June 10, 2020. Revised: November 30, 2020. Accepted: December 12, 2020. Published: December 31, 2020.

\section{Introduction}

The number of students seeking higher education in Bangladesh is increasing in every year. The fundamental requirement of the university is the student. Without student, university cannot survive. The objective of admission policies is to select applicants with the potential to succeed the university studies. At present, public university admission test system in Bangladesh is an epic hassle for higher education seeker. Different universities have different rules for the admission test. Each student is required to buy a separate admission form. At the same university different unit have to apply separately. The minimum qualification, application procedure, admission fees, admission test format, are also different. This cumbersome admission process is challenging both physically and mentally for several lakhs of admission seekers because they have to face a lot of problems regarding accommodation, food and transport. Every year, admission seeker and their guardian face a huge amount of pressure. They travel from one part of the country to another for attending the admission test. Many others fall sick due to the journey. During admission time, traffic system becomes worse. So, many students cannot reach admission centre-right time. They don't have any suitable place to stay. They don't have a well arrangement for taking food. When they take food from outside, they suffer various diseases. Many times, the admission test time is an overlap so the candidate cannot attend all of these universities. When a student admitted to one university, he cannot move to another university easily. If he goes to another university, the vacant seat is created. For calculating the cost in traditional admission system, a survey form was designed. By analysis those data we show that a candidate participates a total of nine universities. Total fifty thousand taka need for attending the university admission test. Not everyone has the ability to spend so much money. It also kills at least five months from the education life of the students to get enrolled in the universities after passing the HSC exams.

The one-test admission system can save from this inconvenience. Our paper design public universities admission system model that serve as 
the proposal to help the admission system for saving time, cost of the candidate and make it flexible.

\section{Conventional Admission System in Different Country}

University admission procedures are different from country to country. Some country has autonomous organizations some country has government agencies which is responsible for organizing admission tests and in some country, university have their own admissions process.

\subsection{Australian Tertiary Admissions Rank (ATAR) Admission System in Australia}

ATAR is a percentile ranking used by universities to assist in the selection of school leavers for entry into undergraduate courses [1]. Typically, selection criteria involve six broad categories: school achievement, aptitude tests, prior study achievement, portfolios, interviews and statements of achievement. ATAR is a rank that indicates a student's position. The courses are developed by the Universities Admissions Centre (UAC).

\subsection{SAT and ACT Admission System in the USA}

In the United States of America (USA), the Scholastic Assessment Test (SAT) and the American College Testing (ACT) are standardized aptitude tests that bear significant importance in the possibility of students being admitted to higher education [2]. The SAT is the exam that will allow you to access the American university system. It is the most recognized exam to gain admission to American universities. The SAT exam pattern having two distinctive formats, namely the SAT Reasoning Test or SAT and SAT Subjects Test. The ACT is a standardized test used for college admissions in the United States. The ACT measures general educational development in four curriculum-based areas: English, mathematics, reading and science. Secondary school performance is a crucial factor, and many institutions, particularly in the elite sector, require a considerable number of application materials, including essays, recommendation letters, interviews, and in some cases, auditions and portfolios. Demographic factors and extra-curricular activities (e.g., participation in sports) are often taken into account as well.

\subsection{United Kingdom Admission System}

In the United Kingdom Students apply through a centralized applications system called Universities and Colleges Admissions System (UCAS) [3]. UCAS manages the applications and admissions process. UCAS provides an online search tool which provides information on what qualifications are acceptable for entry to specific courses in universities across the UK. The application is then forwarded to the relevant institutions, each of which decides whether or not to accept the applicant based on its own standards and criteria. The type of admissions test depends predominantly on the course chosen to study. The exams are subjectspecific tests taken by applicants for Medicine, Philosophy, Politics, Economics, Law, Mathematics and other related courses.

\subsection{Gaokao Admission System in China}

In China, the undergraduate admission system is known as Gaokao. The university system is centrally planned, and admission is centrally coordinated by the national government, which determines the number of spaces available in each institution and program [4]. The Chinese Ministry of Education works closely with Gaokao. Candidates specify the institutions and departments they wish to enter in order of preference and are assigned by the government to an institution and program based on their exam performance and preferences. The format $3+\mathrm{X}$ is the most common, where 3 is the three national compulsory subjects of Chinese, mathematics and a foreign language and $\mathrm{X}$ refers either to arts or science subjects, depending on student choice. The subjects are divided into two groups: science (physics, chemistry, biology) and arts (history, geography and political education). Students choose to follow one or other of these routes, and some versions of the Gaokao have an integrated science or integrated arts test, which assesses all three component subjects at the same time.

\subsection{NCUEE Admission System in Japan}

In Japan The National Centre Test for University Admissions is a type of standardized test used by public and some private universities. The national entrance examination consisting of five to seven subject tests. Test is conducted countrywide on the same day with the same questions by National Centre for University Entrance Examinations, an Independent Administrative Institution (IAI). The function of the Centre Test depends on the institution. The overall score on this exam determines the specific institutions to which a candidate is eligible to apply. Institutions are 
divided into tiers, with higher scores required by more prestigious institutions. Candidates are then required to take a second round of entrance exams, administered individually by each institution to which they apply. Admission is based on a combination of the national and institutional exam scores; each institution determines the relative weight of each [5].

\subsection{Admission Test System in India}

University candidates are admitted to a university in India based on their scores on one or more secondary leaving or entrance exams. These exams are conducted by many different entities, including the national government, provincial governments, individual institutions, and groups of institutions. University candidates are admitted to the university in India based on their scores on one or more secondary leaving or entrance exams. Preference is given more to a student's performance in the tests than their past academic record. The applicants are ranked by their exam grades, and they can choose universities based on their grades. A few major entrance tests conducted for admission into higher professional education such as Joint Entrance Exam, Common Admission Test, Xavier Aptitude Test, National Entrance Screening Test, Common Management Admission Test etc. These exams are conducted by different entities [6].

\subsection{Vestibular Admission in Brazil}

The Vestibular is a main and common competitive entrance examination used by Brazilian universities for their admission processes. This examination is organized by FUVEST (Fundacao Universitaria para o Vestibular). The exam generally lasts for three days, with different fields of study being tested each day [7].

\subsection{Baccalaureate Admission in France}

In France for higher education there contain National exam. Which known as baccalaureate. The general streams are Sciences, Economics and Social Sciences and Literature. There are three main types of baccalaureate: general baccalaureate, professional baccalaureate, technological baccalaureate [8].

In this paper, we have proposed novel approach to reduce the large number of vacant seats, session time and making the whole process transparency.

\subsection{Higher Education System in Bangladesh}

In the case of Bangladesh, higher education called the tertiary level education. In higher education, there contain public and private, medical, university, national university. Before attending the higher education, a student must complete the Secondary School Certificate (SSC) and Higher Secondary Certificate (HSC) examination. In the SSC and HSC program, a student can select three groups such as science, commerce and arts. SSC examinations, is held after ten years of schooling. Next is the Higher Secondary Certificate (HSC) examination held at the end of grade 12. Each public and the private university has an individual admission test. But in medical, there is integrated admission test. In Nation University, there is no admission test; the selection process is conducted by SSC and HSC scores. At present, there are 36 public and 103 private universities in Bangladesh. Public universities are the foremost choice of the majority of students seeking higher education. In this paper, we focus on a public university. Public university types are shown in Fig. 1.

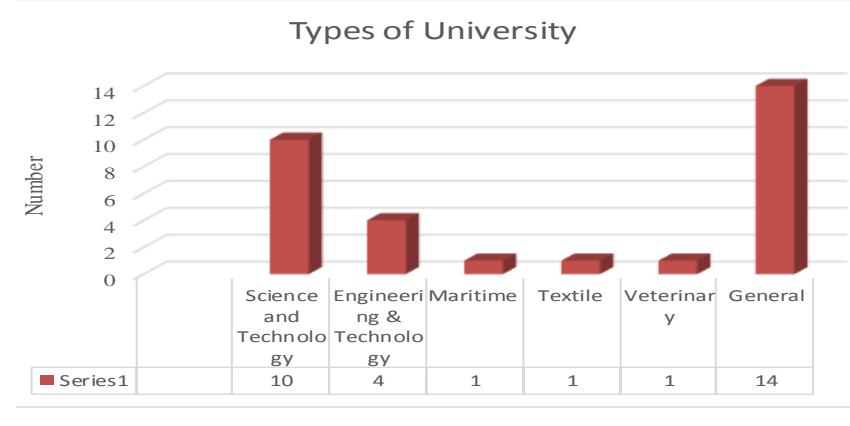

Fig. 1: Types of Public Universities in Bangladesh

In 36 public university total 47381 seat available for new student.

\section{Proposed Model for Admission System in Bangladesh}

Proposed model is aimed at reducing the financial, physical, mental sufferings of the candidate and tensions of the guardian during admission. Proposed three models are namely Integrated Admission System (IAS), University Admission System Based on Subject (UASS), University Admission System Based on Type of University (UAST).

\subsection{Integrated Admission System (IAS)}

In IAS one admission test will be held for all students. That is, one exam will be held for the science background student, one for the commerce background student and one for the arts background 
student. The University Grants Commission is maintaining this admission test and publish the result separately with score and rank for each group. Using this score, the student applies for their desired university individually with filling subject choice. Student can also apply for the group change subject by this score. The university authority selects perfect student using admission test number, SSC, HSC scores, and assigns the subject. The proposed IAS model diagram is shown in Fig. 2. In this system the total number of examinations is three.

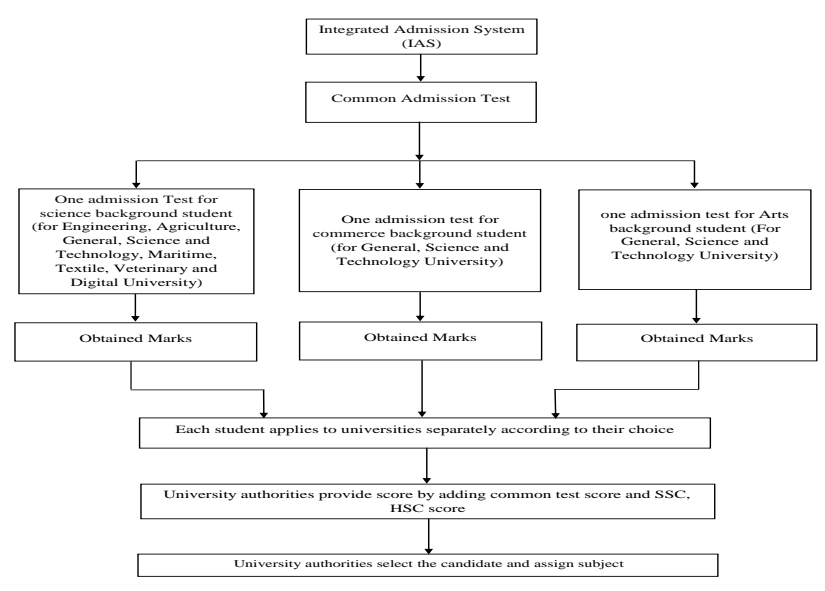

Fig. 2: IAS Model for University Admission

\subsection{Cluster System Admission Based on Subject (CSAS)}

The cluster can be defined as several similar things. In the CSAS model, the cluster is created based on subjects. There is a total of six clusters. Cluster-1 is for all engineering subject. Cluster-2 includes physical science subject. Cluster-3 includes life science subject. Cluster-4 includes commerce related subject. Cluster-5 includes arts-related subject. Cluster-6 includes group change-related subject. Each cluster is taken one exam at a different time. Total examination for this model is six. The University Grants Commission is maintaining this admission and publish the result separately with score and rank for each cluster. Using this score, the student applies for their desired university individually with filling subject choice. The university authority selects perfect student using admission test number, SSC, HSC scores, and assigns the subject. The proposed CSAS model is shown in Fig. 3.

\subsection{Cluster System Admission Based on Type of University (CSAT)}

In CSAT model the cluster is created by the type of university. Cluster-1 includes all engineering, textile university and take a single examination for science background student. Cluster-2 includes all agriculture, veterinary, maritime university and take a single examination for science background student. Cluster-3 include all general university and taken group-based examination for science, commerce and arts background student. Cluster-4 include all science and technology and digital university and taken the group-based examination for science, commerce and arts background student. Total examination for this model is eight. CSAT model is shown in Fig. 4.

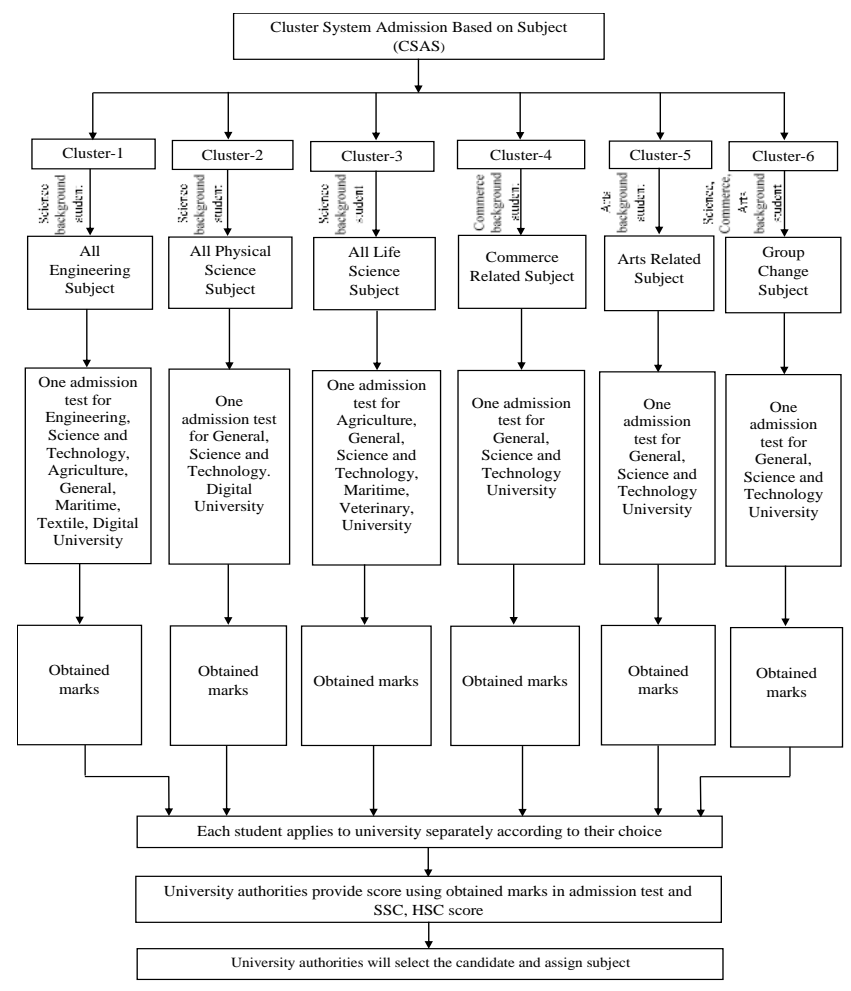

Fig. 3: CSAS Model for University Admission

\subsection{Subject Choice System for CSAT}

Suppose a student is eligible for MBSTU, NSTU, PSTU. By clicking MBSTU candidate could see the eligible department name like Computer Science and Engineering, Information and Communication Technology, Textile Engineering. By clicking PSTU, he could see the qualified department name like Computer Science and Engineering.

Suppose candidate first choice is MBSTU [Computer Science and Engineering] than the first click on the MBSTU than Click on the Computer Science and Engineering. Automatically this subject will be listed and display into in the preferred list as the first choice. If his second choice is NSTU 
[Computer Science and Telecommunication Engineering] than the first click on the NSTU than Click on Computer Science and Telecommunication Engineering. Automatically this subject will be listed

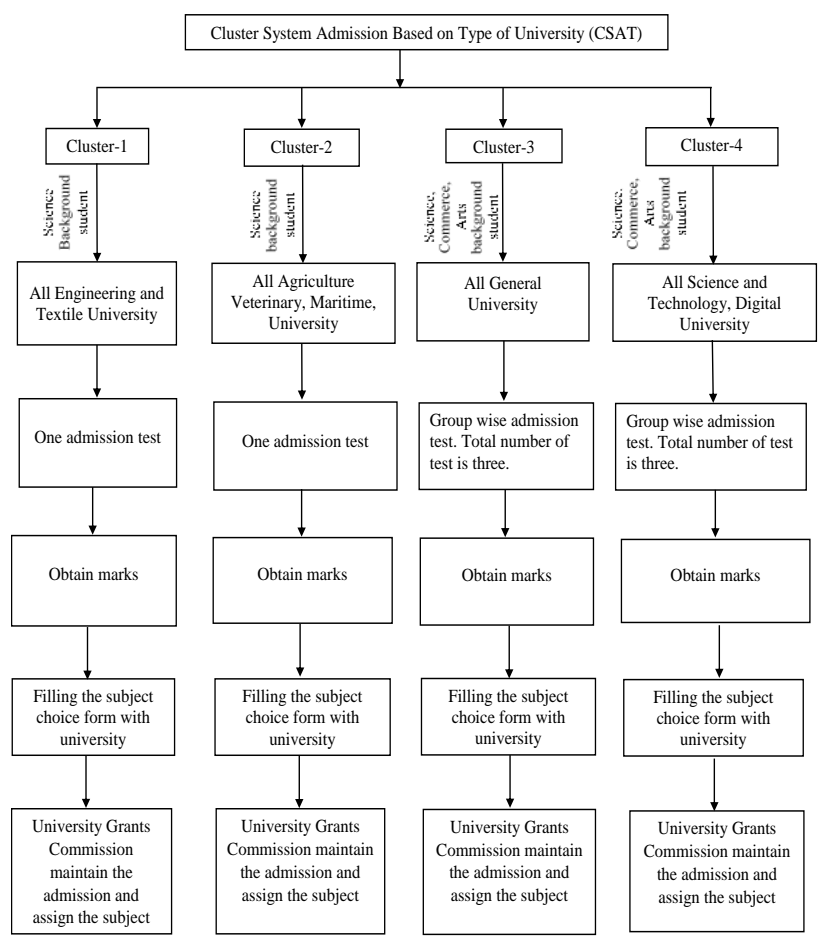

Fig. 4: Proposed CSAT Model for University Admission

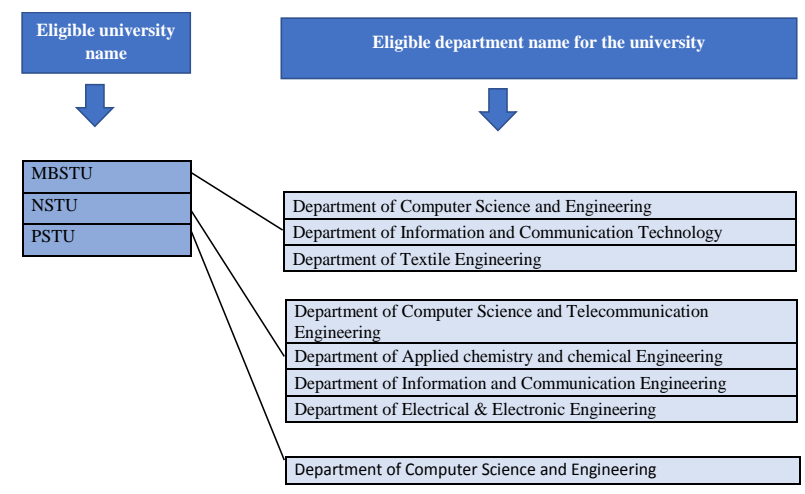

Candidate choice list:

1. MBSTU [Computer Science and Engineering]

NSTU [Computer Science and Telecommunication Engineering]

MBSTU [Information and Communication Technology]

NSTU [Information and Communication Engineering]

PSTU [Computer Science and Engineering]

MBSTU [Textile Engineering]

NSTU [Applied chemistry and chemical Engineering]

8. NSTU [Electrical \& Electronic Engineering]

Fig. 5: Subject Choice List Process for CSAT Model

and display into in the preferred list as the second choice. If his third choice is MBSTU [Information and Communication Technology] than the first click on the MBSTU than Click on Information and Communication Technology. Automatically this subject will be listed and display into in the preferred list as the third choice. And continue this process to fill up the subject choice list. Candidate can add or delete the preference list before submitting the choice form list. The subject is assigning for a student according to their rank and their preferred subject list. Fig. 5 show the choice list process of CSAT model.

Performance testing is the process of determining the speed, responsiveness and stability of the model. Validation test is the process to decide whether or not it satisfies the requirements. Among the three models, any model can be followed for taking public university admission in Bangladesh.

\section{Admission System Management Procedure}

The following measures should be taken for managing the admission system.

- Under the supervision of the University Grants Commission (UGC), a central committee will be set up with three members from each faculty of all public university and seven members from UGC.

- Each university will have to form its own admission test management committee.

- The examiner has to complete the application form online. They will be able to choose a place as the examination center conveniently. The centre will be the university's own campus or in a suitable location.

- A separate committee will be formed to prepare the question paper. Question papers will be done on a Written (MCQ based). For evaluation the answer sheet OMR machine will be used. The pass mark will be $40 \%$ of the total mark. Time of the examination is 2 hours.

- $\quad$ After the passing of the HSC examination, a student will not be allowed to take admission test more than twice.

- $\quad$ Admission test must be taken within 40 to 50 days after the HSC result is published.

- $\quad$ Admission must be completed within 30 days after published the admission test result.

\section{Result and Discussion}

The IAS model is provided with a better result when we consider time, cost, the suffering of a 
candidate. For performance and validity checking survey, the form had been conducted.

\subsection{Time}

For handling the admission system, the proposed model is required less time than the traditional system. Because, in the traditional method, many individual examinations are taken for all university, but in proposed, there is no option of many individual examinations. Among the three proposed model IAS required less time.

\subsection{Cost}

From the student perspective view, the traditional system is high costly than IAS system. Because, in the traditional system, many individual forms cost, travelling, food cost is needed to participate in the examination. But in the IAS model, this cost is less because three is one form cost and student can participate in this admission test into their suitable place.

\subsection{Suffering}

The physical and mental suffering can be reduced by applying the IAS model in the university admission system. Because the number of examinations is one and they need not travels one place to another. By analysis the survey report we can say that $92 \%$ people want to change the traditional system and they support the proposed model. Fig. 6 show the survey report of the traditional and proposed model.

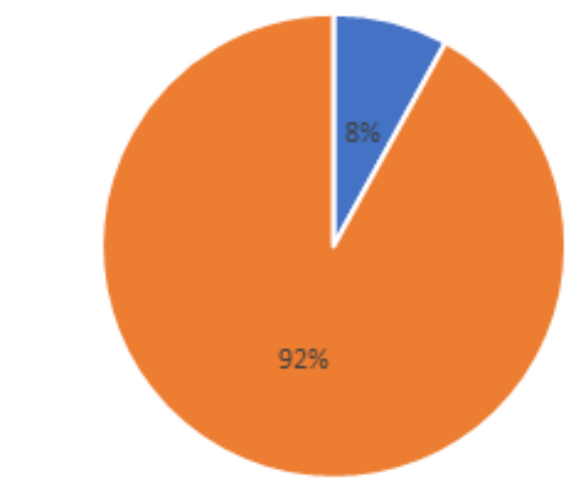

- Traditional System - Proposed Admission system

Fig. 6: Survey Result of Traditional System vs Proposed Admission System

In Fig. 7 survey result of among the proposed three models is shown. Here we show $40 \%$ want IAS, $32 \%$ want CSAT, and $28 \%$ want CSAS admission system.

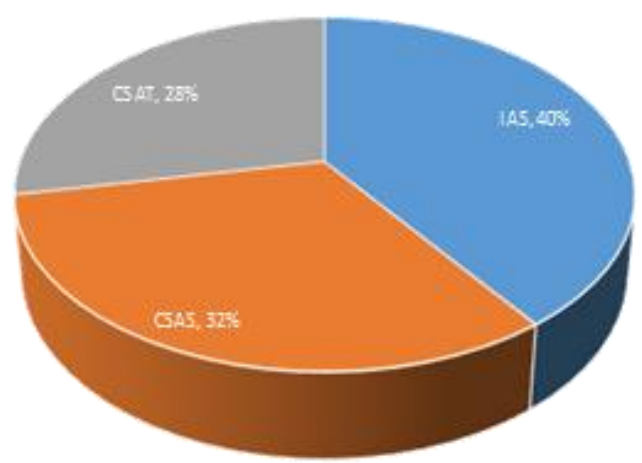

Fig 7: Survey Result Among IAS, CSAS, CSAT Admission System

It is noted that the proposed (IAS) model achieves higher support than the traditional admission system.

\section{Conclusion}

The unified admission test system is nothing new in Bangladesh. Medical colleges have implemented such a system long ago. In this research evaluate the possible admission system model (IAS, CSAS, CSAT), so that we can found the best solution for public university admission test in Bangladesh. It provides a simple method for taking admission. The result of the analysis will assist the academic planners to focus their efforts on taking the admission test. This research presents a model to help reduce the enrolment time of university and more flexible admission system. We have demonstrated various items related to the admission system; this provides perfect accuracy in this research paper. Based on the above findings, the following conclusions are drawn:

- The Proposed Admission Policy is capable of achieving its targets.

- It can give quality students to the university.

- Government expectation becomes valid for taking a combined university admission system.

- Limitations of the existing process are removed by applying this new model.

- This research enhances the quality and ensures the advancement of university admission test system.

- This research achieves excellence in higher education comparable to global standards. 


\section{References}

[1] Kathryn Blyth, "Selection methods for undergraduate admissions in Australia. Does the

Australian predominate entry scheme the Australian Tertiary Admissions Rank (ATAR) have a future?", Journal of Higher Education Policy and Management, Vol. 36, Issue 3, 2014, pp. 268 -278.

[2] Josephine Boland and Madeleine Mulrennan, "Application, selection and admission to higher education: a review of international practice", Higher Education Authority and National Council for Curriculum and Assessment, 2011. pp 45-59.

[3] Josephine Boland and Madeleine Mulrennan "Application, selection and admission to higher education: a review of international practice", 2011, pp 61-89.

[4]. Abdulghani Muthanna," Undergraduate Chinese students' perspectives on Gaokao examination: Strengths, weaknesses, and implications", International Journal of Research Studies in Education, 2015.

[5] Yoshinori Watanabe," The National Center Test for University Admissions" SAGE Journals, Vol. 30, Issue 4, 2013, pp. 565-573.

[6] Helms \& Robin Matross; Helms, Robin Matross "University admission worldwide (English)", Education working paper series no. 15. Washington, DC: World Bank,2008. http://documents.worldbank.org/curated/en/671131 468153295738/University-admission-worldwide.

[7] Renato H. L. Pedrosa, "Access to higher education in Brazil", Widening Participation and Lifelong Learning, vol. 16, Number 1, 1 May 2014.

[8] Durazzi \& Niccolo "Higher education entrance qualification and exams in Europe: a comparison" 2014. pp 25-50, 2014.

\section{Creative Commons Attribution License 4.0 (Attribution 4.0 International, CC BY 4.0)}

This article is published under the terms of the Creative Commons Attribution License 4.0

https://creativecommons.org/licenses/by/4.0/deed.en_US 